\title{
Enucleation Surgery-Orbital Implants and Surgical Techniques
}

\author{
Yacoub A Yousef \\ Department of Surgery, King Hussein Cancer Center, Amman, Jordan
}

DOI: http://doi.org/10.17925/USOR.2016.09.01.46

\begin{abstract}
Enucleation consists of surgical removal of the entire eye globe with preservation of the conjunctiva, extraocular muscles, orbital fat, and optic nerve. This surgical procedure is generally accepted treatment for intraocular malignancies, blind painful eye, severely traumatized eye, phthisis bulbi, and to improve cosmetic appearance. Once the eye is removed, orbital volume enhancement typically requires implantation of spherical materials that can be classified into two major groups: non-porous and porous orbital implants. Different surgical techniques have been described in the literature, including muscle imbrication technique and the myoconjunctival enucleation technique (both with a non-integrated implant) and the more recent integrated orbital implants technique that results in less implant-migration and improved prosthesis movement. In this review, we discuss indications, orbital implant choices and the main enucleation surgical techniques reported in the literature.
\end{abstract}

\section{Keywords}

Enucleation, porous orbital implant, rectus muscle, tumor

Disclosure: Yacoub A Youssef has nothing to declare in relation to this article. No funding was received in the publication of this article.

Open Access: This article is published under the Creative Commons Attribution Noncommercial License, which permits any noncommercial use, distribution, adaptation, and reproduction provided the original author(s) and source are given appropriate credit.

Received: February 9, 2016 Accepted: February 17, 2016 Citation: US Ophthalmic Review, 2016;9(1):46-8

Correspondence: Yacoub A Yousef, Consultant Ocular Oncologist, King Hussein Cancer Centre, Queen Rania Street, PO Box 1269 Al-Jubeiha, Amman 11941 Jordan.

E: yyousef@khcc.jo

Enucleation, or surgical removal of the entire eye globe, was described by Bartisch in 1583, and was described in combination with orbital volume replacement (implant) by Mules in $1585 .{ }^{1-3}$ In the US, trauma is the leading indication for enucleation (40.9\% of cases), followed by tumors (28\% of cases). ${ }^{4,5}$ Other indications include painful blind eye, phthisis with degeneration, congenital anophthalmia, severe microphthalmia, unresponsive endophthalmitis, and for improvement of cosmesis in a blind eye. ${ }^{4}$

Various materials may be used to create orbital implants, including cartilage, bone, fat, gold, silver, cork, rubber, aluminum, ivory, silk, wool, petroleum jelly, acrylics, silicone, glass, titanium, quartz, and porous materials such as hydroxyapatite (HA) and polyethylene. ${ }^{6-15}$ Unfortunately, however, several reports describe the associated complications of using such materials, such as exposure, displacement, extrusion, and orbital infection. 7,14,16

The orbital implant and overlying prosthesis work together to allow excellent overall cosmesis and eye movement after enucleation. Most patients are pleased with the result and few require secondary cosmetic surgery. After healing, the appearance of the anophthalmic patient's affected eye should be similar in all aspects to their other, normal eye. ${ }^{17}$ Herein, we briefly review the main types of orbital implants, and the main enucleation surgical techniques reported in the literature.

\section{Types of Implants and Enucleation Surgical Techniques}

In the modern era, several types of orbital implants are available for volume replacement after removal of the eye. They can be classified into two major groups: non-integrated orbital implants (primarily polymethylmethacrylate [PMMA]) and integrated porous orbital implants (typically plastic, bone, or coral). ${ }^{18-24}$ The difference between these two major groups is that integrated implants allow fibrovascular invasion or incorporation into the living orbit. Graue and Finger demonstrated that on positron emission tomography (PET)/computed tomography (CT) imaging, porous orbital implants absorb 18-fluorodeoxyglucose contrast, indicating metabolic activity within the implanted device. ${ }^{25}$ That fibrovascular invasion does not occur with non-integrated implants.

\section{Surgical Techniques}

Enucleation surgery is usually done under general anesthesia. First, the surgeon resects the conjunctiva from the surgical limbus (periotomy), followed by dissection of the Tenon's capsule (tenotomy). Then the four recti muscles (with or without the two oblique muscles) need to be isolated, tied by 6-0 absorbable suture, followed by muscle resection from the insertion, and homeostasis. Then the eye globe should be pulled anteriorly (either from the stump of the medial rectus, assisted by cryotherapy, or by sutures at the limbus from two sites), followed by resection of the optic nerve (the length should be $8-12 \mathrm{~mm}$ in cases of 


\section{Table 1: The Differences Between the Three Main Enucleation Surgical Techniques}

\begin{tabular}{|c|c|c|c|}
\hline & Imbrication Technique $\mathrm{e}^{20,24,26}$ & Integrated Implant Technique ${ }^{12-15,27,28}$ & Mycoconjunctival Technique 29,30 \\
\hline Type of implant & Non-integrated & Integrated (porous) & Non-integrated \\
\hline Implant material (commonly used) & PMMA or silicone & Hydroxyapatite or polyethylene & PMMA \\
\hline Need for mesh around the implant & No & Yes & No \\
\hline Repositioning the rectus muscles & $\begin{array}{l}\text { Superior rectus imbricated with inferior } \\
\text { rectus, and medial rectus imbricated with } \\
\text { lateral rectus }\end{array}$ & $\begin{array}{l}\text { Muscles directly sutured to the scleral } \\
\text { cap or the mesh around the implant in } \\
\text { a location corresponding to muscle } \\
\text { insertion }\end{array}$ & $\begin{array}{l}\text { Recti muscles sutured just short of the } \\
\text { respective fornices with sutures passing } \\
\text { through the anterior Tenon's-conjunctival } \\
\text { complex }\end{array}$ \\
\hline Repositioning the oblique muscles & No & Yes & No \\
\hline Postoperative care & \multicolumn{3}{|c|}{ Eye patch for $2-5$ days and prophylactic systemic and topical antibiotics for 2 weeks } \\
\hline Main complications & Implant displacement and extrusion & Persistent infection, and implant exposure & Implant extrusion \\
\hline Cost & cheap & Expensive & cheap \\
\hline
\end{tabular}

PMMA = polymethylmethacrylate.

retinoblastoma). Then a plastic or metallic dummy implant can be used to check the best size for the orbital implant (i.e. the maximum size that fills the orbit and allows adequate suturing of the anterior layers without tension). Once the required size is identified, the selected implant should be inserted deep in the socket (with or without implant injector), and deeper than the posterior Tenon's layer. Table 1 illustrates the differences between the three main enucleation surgical techniques.

After fixation of the implant in the correct site and attachment of the muscles according to technique, the posterior and anterior parts of the Tenon's capsule will be sutured by absorbable interrupted sutures (5-0 or 6-0) separately, followed by closure of the conjunctiva by running 6-0 absorbable suture. In the case of the myoconjunctival technique, then the exteriorized muscle sutures are tied onto the conjunctival surface and the suture knot left exposed.

To maintain the fornices and to prepare them for prosthesis fitting (usually six weeks after enucleation), a conformer of adequate size (small, medium, or large) needs to be inserted anterior to the sutured conjunctiva, with topical antibiotic and tight patching of the eye for two to five days. An alternative to the conformer is immediate painted prosthesis insertion at the time of the surgery, or early prosthesis insertion at the time of patch removal, to allow for cosmetic rehabilitation and improved quality of life. This prosthesis may need to be replaced by a custom-made one after six weeks. ${ }^{31,32}$

\section{Discussion}

An ideal orbital implant and surgical technique should yield excellent prosthesis motility and cosmesis, with very few complications. The technique includes choosing an appropriately sized implant, positioning the implant deeply in the orbit, meticulously closing the Tenon capsule over the implant, and securing the conjunctiva over the implant without tension.

Imbrication of the rectus muscles over a non-integrated implant traditionally was thought to impart movement to the implant and prosthesis. Like a ball-and-socket joint, when the implant moves, the prosthesis on surface moves. However, because the so-called ball and socket are separated by layers of Tenon's capsule, imbricated muscles, and conjunctiva, the mechanical efficiency of transmission of movement from the implant to the prosthesis is suboptimal. In addition to that, imbrication of the recti over the smooth surface of nonintegrated implants can result in implant displacement and migration. ${ }^{12-15}$

Integrated porous implants have been used for more than two decades now and they provide better implant movement than the traditional non-integrated implants because of direct attachment of extraocular muscles to the implant, ${ }^{33}$ and they are associated with less migration and extrusion. ${ }^{5,33}$ Custer et al. ${ }^{34}$ reported that there was no difference in implant movement when sclera-wrapped non-integrated implants and sclera-wrapped integrated implants were compared, thus indicating that the implant material itself may not have a bearing on implant movement, as long as the muscles are attached directly or indirectly to the implant. Although the porous implants have been reported to offer improved implant movement, ${ }^{35}$ these are more expensive and intrusive, requiring wrapping, and also are prone to implant exposure. ${ }^{33}$

The cosmetic appearance of the prosthesis ${ }^{36,37}$ and implant migration and extrusion $^{37,38}$ are subjective outcome measures, while implant and prosthesis movement are objective, and hence were used as the primary outcome measure in a randomized controlled trial by Shome et al., ${ }^{30}$ who compared the differences in implant and prosthetic movement after myoconjunctival enucleation (with non-integrated PMMA implant) with those of two other standard techniques: the traditional muscle imbrication technique (with non-integrated PMMA implant) and enucleation with integrated porous polyethylene implant. They found that myoconjunctival PMMA implant movement was better than the traditional PMMA implant, and was similar to that of the porous polyethylene implant. Even more, prosthesis movement with the myoconjunctival PMMA implant was better than that with either the traditional PMMA or porous polyethylene implants. ${ }^{30}$

An important aspect of implant movement is the contraction of the rectus muscles. According to the Starling hypothesis, ${ }^{39}$ muscle contraction is compromised by undue stretching beyond its original length, and this is believed to have been responsible for the decreased implant movement after the traditional imbrication technique. This poor implant movement in turn leads to poor prosthesis movement because spherical implants impart movement to the prosthesis by providing a smooth pivotal surface 
over which the prosthesis glides passively. This probably accounted for the poorer prosthesis movement in the traditional PMMA group compared with the myoconjunctival technique, where each muscle is sutured to the respective fornix, thus avoiding stretching. One more reason for that difference is that the muscle imbrication over the anterior surface of the implant is associated with higher rate of implant displacement, while the deep orbital placement of the implant, the secure posterior Tenon's capsule over it, and the suturing of the extraocular muscles to the fornices in the myoconjunctival PMMA implant technique might have helped implant centration better. ${ }^{26,29}$

The prosthesis movement associated with the myoconjunctival PMMA implant was better than with the integrated porous polyethylene implant. That is possibly because the attachment of the extraocular muscle to the fornices causes exaggerated deepening and shallowing of the fornices when the patient attempts to look in different directions, thereby causing further enhanced prosthesis movement.

Unfortunately, many complications are associated with integrated implants. Rates of exposure and postoperative inflammation of integrated
HA implants range from $0 \%$ to $22 \%,{ }^{15,30-44}$ while it is almost (0\%) for silicone implants. ${ }^{45}$ Buettner and Bartley ${ }^{42}$ proposed that exposure of HA implants is related to the inflammatory reaction incited by the implant or by delayed fibrous ingrowth. Goldberg et al. ${ }^{46}$ suggested that use of HA implants, even with exposure, was less likely to lead to extrusion or infection compared with exposure with silicone or acrylic implants. Shields et al. ${ }^{47}$ described 100 cases of HA implants, among which they reported six patients with excessive postoperative orbital pain, two patients with wound edema, and one patient with erosion. In another report of 250 cases they described eight patients with conjunctival thinning, four patients with erosions, and one with orbital infection. ${ }^{48}$

\section{Conclusion}

In conclusion, orbital implants have been used for more than a century. Serious complications can occur, but they do so infrequently. Different surgical techniques were described in the literature; both the myoconjunctival enucleation technique (with non-integrated implant) and the integrated porous orbital implant technique result in better implant and prosthesis movement than the traditional muscle imbrication enucleation technique with a PMMA implant.
1. Soares IP, França VP, Evisceration and enucleation, Semin Ophthalmol, 2010;25:94-7.

2. Luce $\mathrm{CM}, \mathrm{A}$ short history of enucleation, Int Ophthalmol Clin 1970:10:681-7.

3. Gougelman $\mathrm{HP}$, The evolution of the ocular motility implant, Int Ophthalmol Clin, 1970;10:689-711

4. Shah RD, Singa RM, Aakalu VK, Setabutr P, Evisceration and enucleation: a national survey of practice patterns in the United States, Ophthalmic Surg Lasers Imaging, 2012;43:425-30.

5. Moshfeghi DM, Moshfeghi AA, Finger PT, Enucleation, Surv Ophthalmol, 2000:44:277-301.

6. Chaudhry IA, AIKuraya HS, Shamsi FA, et al., Current indications and resultant complications of evisceration, Ophthalmic Epidemiol, 2007;14(2):93-7.

7. Anderson RL, Thiese SM, Nerad JA, et al., The Universal orbital implant: indications and methods, Adv Ophthal Plast Reconstr Surg, 1990;888-99.

8. Tyers AG, Collin JR, Baseball orbital implants: a review of 39 patients, Br I Ophthalmol, 1985:69:438-42.

9. Helms HA, Zeiger HE Jr, Callahan A, Complications following enucleation and implantation of multiple glass spheres in the orbit, Ophthal Plast Reconstr Surg, 1987;387-9.

10. Hornblass A, Herschorn BJ, Double sphere orbital implantation in enucleation and evisceration, Ophthal Plast Reconstr Surg, $1985 ; 165-8$.

11. Jacob-LaBarre JT, DiLoreto DA, Total integration of an ocular implant/prosthesis: preliminary in vivo study of a new design, Ophthal Plast Reconstr Surg, 1995:11200-8.

12. Karesh JW, Dresner SC, High density porous polyethylene (Medpor) as a successful anophthalmic socket implant Ophthalmology, 1994;101:1688-96.

13. Morax S, Use of GORE-TEX (polytetrafluoroethylene) in the anophthalmic socket, Adv Ophthalmic Plast Reconstr surg, 1990:882-7.

14. Perry AC, Integrated orbital implants, Adv Ophthal Plast Reconstr Surg, 1990;875-81.

15. Remulla HD, Rubin PA, Shore JW et al., Complications of porous spherical orbital implants, Ophthalmology, 1995;102,586-93.

16. Shields $C L$, Shields JA, De Potter P, Singh AD, Problems with the hydroxyapatite orbital implant: experience with 250 consecutive cases, Br J Ophthalmol, 1994;78:702-6.

17. Schaefer DP, Rocca RC, Enucleation. In: Nesi FA, Lisman RD, Levine MR, eds., Smith's Ophthalmic Plastic and Reconstructive Surgery, 2nd ed. St. Louis, MO: Mosby, 1998;1015-52.

18. Beard $\mathrm{CH}$, Ophthalmic Surgery: A Treatise on Surgica Operations Pertaining to the Eye and Its Appendages, with Chapters on Para-Operative Technique and Management of
Instruments, Philadelphia: Blakiston, 1910:457-77.

19. Anderson RL, Thiese SM, Nerad JA, et al., The universal orbital implant: indications and methods, Adv Ophthalmic Plast Reconstr Surg, 1990;8:88-99.

20. Beard C, Remarks on historical and newer approaches to orbita implants, Ophthalmic Plast Reconstr Surg, 1995;11:89-90.

21. Girard L, Eguez I, Soper JW, et al., Buried quasi-integrated enucleation implant of Proplast II: a preliminary report, Ophthalmic Plast Reconstr Surg, 1990;6:141-3.

22. Karesh JW, Dresner SC, High-density porous polyethylene (Medpor) as a successful anophthalmic socket implant, Ophthalmology, 1994;101:1688-95; discussion 1695-6.

23. Migliori ME, Putterman AM, The domed dermis-fat graft orbital implant, Ophthalmic Plast Reconstr Surg, 1991;7:23-30

24. Hornblass A, Biesman BS, Eviatar JA, Current techniques of enucleation: a survey of 5,439 intraorbital implants and a review of the literature, Ophthalmic Plast Reconstr Surg, 1995;11:7786: discussion 87-8.

25. Graue GF, Finger PT, Physiologic positron emission tomography/ CT imaging of an integrated orbital implant, Ophthal Plast Reconstr Surg, 2012;28:e4-6.

26. Allen $\mathrm{L}$, The argument against imbricating the rectus muscles over spherical orbital implants after enucleation Ophthalmology, 1983;90:1116-20.

27. Shields CL, Shields JA, Eagle RC, De Potter P, Histopathologic evidence of fibrovascular ingrowth four weeks after implantation of the hydroxyapatite orbital implant, $A m$ Ophthalmol 1991:111:363-6.

28. Sires $\mathrm{BS}$, Holds JB, Archer $\mathrm{CR}$, et al., Histological and radiologica analyses of hydroxyapatite orbital implants in rabbits, Ophthal Plast Reconstr Surg, 1995;11:273-7.

29. Nunery WR, Chen WP, Enucleation and evisceration. In: Bosniak SL, ed., Principles and Practice of Ophthalmic Plastic and Reconstructive Surgery, vol. 2, Philadelphia: Saunders, $1996 ; 1035-45$

30. Shome D, Honavar SG, Raizada K, Raizada D, Implant and prosthesis movement after enucleation: a randomized controlled trial, Ophthalmology, 2010;117:1638-44.

31. Chin K, Margolin CB, Finger PT, Early ocular prosthesis insertion improves quality of life after enucleation, Optometry, 2006;77:71-5.

32. Vincent $\mathrm{AL}$, Webb MC, Gallie BL, Héon E, Prosthetic conformers: a step towards improved rehabilitation of enucleated children, Clin Experiment Ophthalmol, 2002:30:58-9.

33. Shields CL, Shields JA, De Potter P, Singh AD, Problems with the hydroxyapatite orbital implant: experience with 250 consecutive cases, Br J Ophthalmol, 1994;78:702-6.
34. Custer PL, Trinkaus KM, Fornoff J, Comparative motility of hydroxyapatite and alloplastic enucleation implants, Ophthalmology, 1999:106:513-6.

35. Jordan DR, Chan S, Mawn L, et al., Complications associated with pegging hydroxyapatite orbital implants, Ophthalmology 1999;106:505-12.

36. Goldberg RA, Dresner SC, Braslow RA, et al., Animal mode of porous polyethylene orbital implants, Ophthalmic Plast Reconstr Surg, 1994:10:104-9.

37. Karcioglu ZA, al-Mesfer SA, Mullaney PB, Porous polyethylene orbital implant in patients with retinoblastoma, Ophthalmology, 1998:105:1311-6.

38. Soll DB, The anophthalmic socket, Ophthalmology, 1982;89:407-23.

39. Nunery WR, Hetzler KJ, Improved prosthetic motility following enucleation, Ophthalmology, 1983;90:1110-15.

40. De Potter $P$, Shields $C L$, Shields JA, singh $A D$, Use of the hydroxyapatite ocular implant in the pediatric population, Arch Ophthalmol, 1994:112:208-12.

41. Hornblass A, Biesman BS, Eviatar JA, Current techniques of enucleation: a survey of 5,439 intraorbital implants and review of the literature, Ophthal Plast Reconstr Surg, 1995; 11:77-88

42. Buettner H, Bartley GB, Tissue breakdown and exposure associated with orbital hydroxyapatite implants, $A m$ J Ophthalmol, 1992:113:669-73.

43. Kaltreider SA, Newman SA, Prevention and management of complications associated with the hydroxyapatite implants, Ophthal Plast Reconstr Surg, 1996;1218-31.

44. Oestreicher JH, Liu E, Berkowitz M, Complications of hydroxyapatite orbital implants: a review of 100 consecutive cases and a comparison of Dexon mesh (polyglycolic acid) with scleral wrapping, Ophthalmology, 1997;104:324-9.

45. Nunery WR, Heinz GW, Bonnin JM, et al., Exposure rate of hydroxyapatite spheres in the anophthalmic socket: histop sphere implants, Ophthal Plast Reconstr Surg, 1993:996-104.

46. Goldberg RA, Holds JB, Ebrahimpour J, Exposed hydroxyapatite orbital implants: report of six cases, Ophthalmology, 1992;99:831-6.

47. Shields CL, Shields JA, De Potter P, Hydroxyapatite orbital implant after enucleation: experience with initial 100 consecutive cases, Arch Ophthalmol, 1992;110:333-8.

48. Shields $C L$, Shields JA, De Potter P, singh AD, Lack of complications of the hydroxyapatite orbital implant in 250 consecutive cases, Trans Am Ophthalmol Soc, 1993;91:177-95. 